Tabela 1 - Número de electrões de valência dos elementos mais usuais nos compostos orgânicos e localização desses mesmos elementos na Tabela Periódica.

\begin{tabular}{cccc}
\hline $\begin{array}{c}\text { Símbolos } \\
\text { dos elementos }\end{array}$ & $\begin{array}{c}\text { Número de } \\
\text { electrões de valência }\end{array}$ & $\begin{array}{c}\text { Grupo na } \\
\text { Tabela Periódica }\end{array}$ & $\begin{array}{c}\text { Período da } \\
\text { Tabela Periódica }\end{array}$ \\
$\mathrm{N}, \mathrm{P}$ & 4 & 14 & $2 .^{\circ}$ \\
$\mathrm{O}, \mathrm{S}$ & 5 & 15 & $\mathrm{~N}$ no $2 .^{\circ} ; \mathrm{P}$ no $3 .^{\circ}$ \\
$\mathrm{F}, \mathrm{Cl}, \mathrm{Br}, \mathrm{I}$ & 6 & 16 & $\mathrm{O}$ no $2 .^{\circ} ; \mathrm{S}$ no $3 .^{\circ}$ \\
\hline
\end{tabular}

4, o azoto tem 5, o oxigénio tem 6 e o flúor tem 7. No entanto, sempre que um dado átomo tem pares de electrões não compartilhados, ele pode cedê-los a uma espécie que os não tenha - por exemplo, um protão, e forma-se assim uma nova ligação química. É o que acontece com o amoníaco e a água, respectivamente, para originarem o ião amónio, $\mathrm{NH}_{4}^{+}$, e o ião oxónio, $\mathrm{H}_{3} \mathrm{O}^{+}$. Repare-se agora que, considerando o que se disse acima, é como se o átomo de azoto em $\mathrm{NH}_{4}{ }^{+}$só possuísse 4 electrões - tem menos 1 electrão do que o seu número de electrões de valência, logo fica com carga positiva. 0 mesmo acontece com o oxigénio - é como se só possuísse 5 electrões, logo também fica com carga positiva. Diz-se então que os átomos de azoto e oxigénio, respectiva- mente nos iões amónio e oxónio, apresentam carga formal positiva.

A figura 1B também exemplifica um outro conceito excepcionalmente importante em Química e que é o de ácidos e bases segundo a definição de Lewis. Toda a espécie que pode ceder pares de electrões para formar novas ligações químicas é uma base, enquanto que a espécie que os recebe é o ácido. Logo, 0 amoníaco e a água são bases e o $\mathrm{H}^{+}$é um ácido.

Outro pormenor importante a retirar da figura 1B é o sentido das setas curvas: repare-se que estas, em Química Orgânica, denotam sempre o sentido do deslocamento dos electrões, e têm o aspecto exemplificado (—) para o deslocamento de pares de electrões.
Esta convenção faz com que uma seta curva comece numa ligação covalente ou num par de electrōes não compartiIhado de um dado átomo e aponte para um átomo de uma espécie com deficiência nos mesmos.

Na figura $1 \mathrm{C}$ está representada a estrutura do borano, uma molécula altamente reactiva devido ao facto do boro não estar rodeado por 8 electrões (como se explicou anteriormente, a verificação da regra do octeto para um átomo do 2 . $^{\circ}$ período é uma condição de estabilidade). Em presença de um ião hidreto, também altamente reactivo (uma espécie de hidrogénio com 2 electrões, logo com carga formal negativa), o que acontece é que os electrōes do ião hidreto vão estabelecer uma nova ligação química com o boro, ficando este átomo a figura 1

parte A Estruturas de Lewis do metano, amoníaco, água e ácido fluoridrico; parte B: Formação dos iões amónio e oxónio; parte C: Formação do iāo borohidreto.

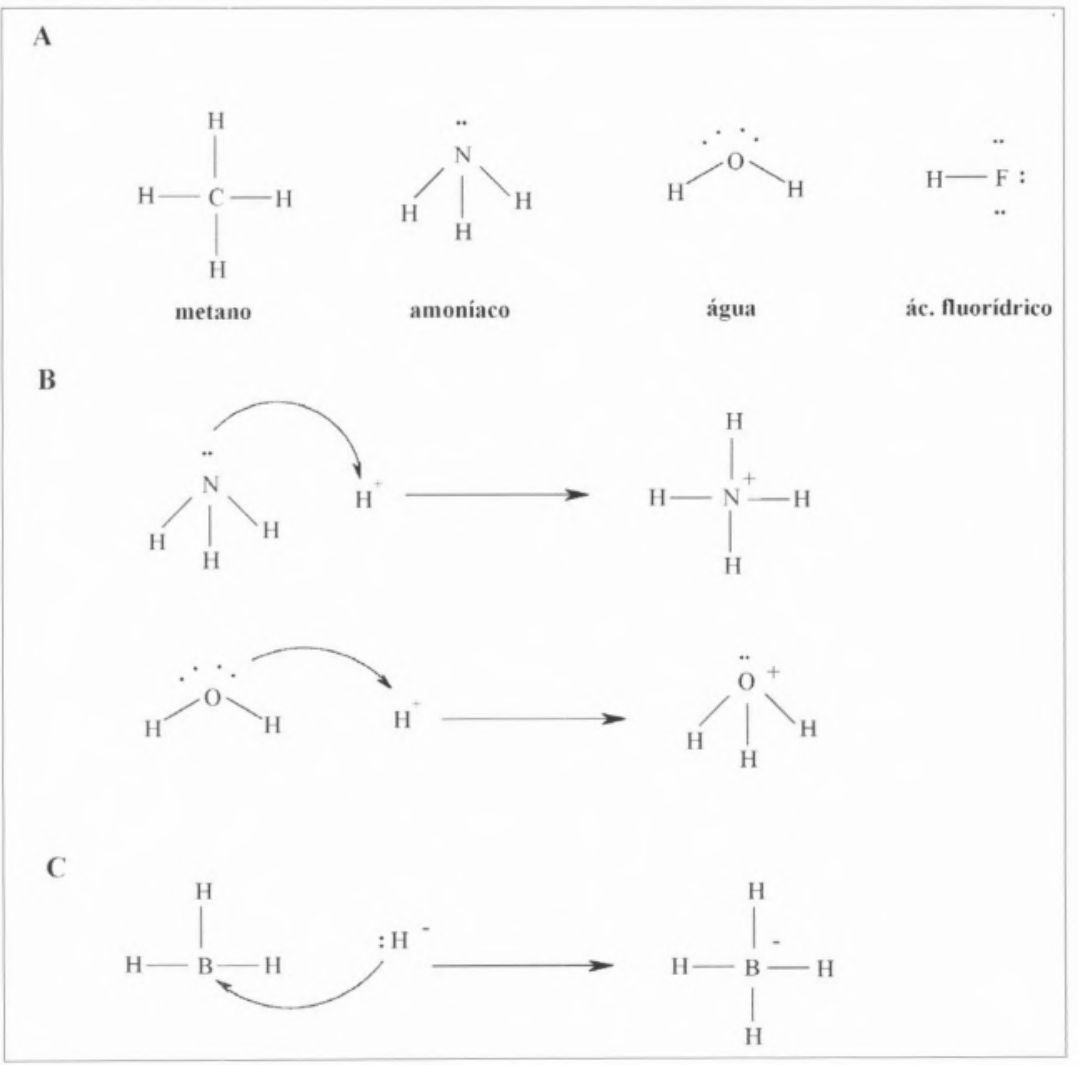




\section{Hidrogénio e o desenvolvimento sustentável}

\section{Interesse da actividade}

Nesta actividade será montada, com material acessivel, uma tina para realizar a electrólise da água, com a possibilidade colectar os gases formados. Poder-se-à discutir as reacções envolvidas de em cada eléctrodo, e as perspectivas da utilização do hidrogénio como fonte de energia alternativa, como por exemplo a sua utilização em células de combustivel. Deve-se realçar que a utilização de hidrogénio como fonte de energia cria um ciclo fechado, da água ao hidrogénio, e do hidrogénio de volta a água, onde se eliminam os subprodutos poluentes que existem na utilização de combustiveis fósseis. As implicações, no futuro, das opções energéticas do presente, a necessidade de procurar uma via de desenvolvimento que seja sustentável, recorrendo a energias renováveis e não poluentes, assim como a necessidade de transformar os processos químicos actuais por forma a minimizar ou anular o seu impacto ambiental, são preocupaçōes a que o químico de hoje não pode alhear-se.

\section{Acerca da da actividade}

O hidrogénio é um combustivel, as experiências devem ser feitas com as devidas precauções e longe de qualquer fonte de ignição.

\section{Introdução histórica}

O Químico e Físico britânico Henry Cavendish ${ }^{1}$, foi quem pela primeira vez, em 1766, isolou e estudou as propriedades fisicas do hidrogénio, gerado através da reaç̧ão de metais com ácidos, como no caso do zinco:

$$
\mathrm{Zn}(\mathrm{s})+2 \mathrm{H}^{+}(\mathrm{aq}) \rightarrow \mathrm{Zn}^{2}+(\mathrm{aq})+\mathrm{H}_{2}(\mathrm{~g})
$$

Observando que este explodia quando aquecido em contacto com o ar, chamou-o de "ar inflamável". O químico Joseph Priestley², seu contemporêneo e compatriota, observou a formação de humidade nas paredes do tubo, após a explosão. Juntos investigaram a matéria formada (água) e provaram pela primeira vez que a água era um composto de oxigénio e hidrogénio. Foi o químico francês Lavoisier ${ }^{3}$ quem deu ao gás o nome de hidrogénio, que significa "espirito da água", ou "formador de água".

$$
\mathrm{H}_{2}(\mathrm{~g})+1 / 2 \mathrm{O}_{2}(\mathrm{~g}) \rightarrow \mathrm{H}_{2} \mathrm{O}
$$

Desde os inícios do século XIX que os cientistas reconheceram o hidrogénio como uma fonte potencial de combustivel. Em 1839, o Físico britânico William Grove ${ }^{4}$ produziu a primeira célula de combustivel. Baseando-se na electrólise da água, Grove tentou reverter a reacção, combinando oxigénio e hidrogénio para produzir electricidade e água. Este é o princípio básico da célula de combustivel.

No final dos anos 50, a NASA precisou pensar em geradores de electricidade para missões espaciais. O projecto Apollo e as missões espaciais Shuttle fizeram uso das células de combustivel.

As células de combustivel são pilhas que convertem energia quimica directamente em energia eléctrica, operando continuamente graças à alimentação constante com um combustivel.

A conversão ocorre por meio de duas reacções químicas parciais que ocorrem em dois eléctrodos separados por um electrólito apropriado: a oxidação do combustivel no ânodo e a redução de um oxidante no
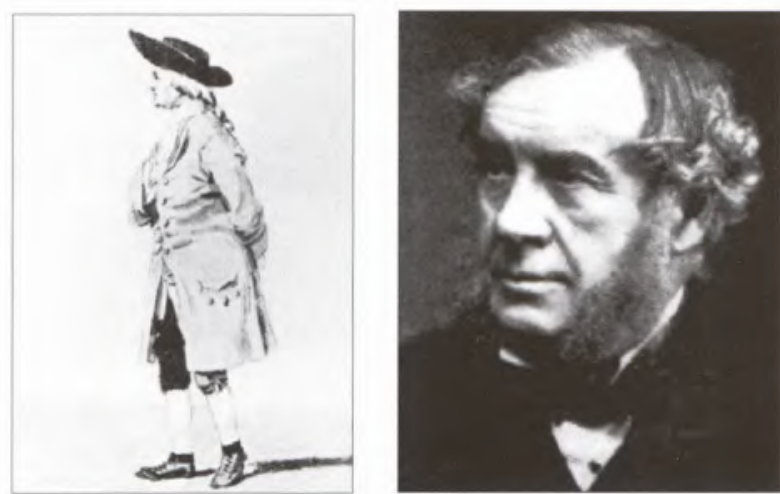

Henry Cavendish (1731-1810)

Sir William Grove (1811-1896)

cátodo. Utilizando o hidrogénio como combustivel e o oxigénio como oxidante, na célula de combustivel dá-se formação de água. Os electrōes que circulam do ânodo para o cátodo podem gerar trabalho eléctrico. Os protōes gerados na reacção anódica (oxidação do hidrogénio) são conduzidos pelo electrólito até ao cátodo, onde se ligam aos aniões $\mathrm{O}^{2}$, produto da redução do oxigénio, formando água. Várias animações de células de combustivel a funcionar podem ser vistas na internet. ${ }^{5}$

O hidrogénio é hoje usado nas naves espaciais como combustivel de propulsão, e para gerar electricidade, produzindo a água que os astronautas bebem. Com mais um pouco de investigação e desenvolvimento este combustivel pode servir como uma fonte de energia alternativa para aquecer e iluminar casas, gerar electricidade, e alimentar motores de veículos. A Câmara Municipal do Porto tem, desde 10 de Janeiro de 2004, em funcionamento três autocarros alimentados a hidrogénio, numa iniciativa exemplar para um desenvolvimento sustentável. ${ }^{6}$ Quando produzido a partir de fontes de energia renováveis, como a hidráulica, a solar e a eólica, o hidrogénio torna-se um combustivel renovável.

\section{Resposta às Questões}

2 - Cátodo: $2 \mathrm{H}^{+}(\mathrm{aq})+2 \mathrm{e} \rightarrow \mathrm{H}_{2}(\mathrm{~g})$

Ânodo: $2 \mathrm{H}_{2} \mathrm{O} \rightarrow 4 \mathrm{H}^{*}(\mathrm{aq})+\mathrm{O}_{2}(\mathrm{~g})+4 \mathrm{e}$

3 - Hidrogénio.

\section{Notas}




\section{Hidrogénio e o desenvolvimento sustentável}

0 hidrogénio é o elemento mais simples e mais abundante no universo. Alguns cientistas acreditam que ele é a fonte de todos os outros elementos, através do processo de fusão nuclear.Tem o maior conteúdo de energia por unidade de peso $(120.7 \mathrm{~kJ} / \mathrm{g})$ de todos os combustiveis conhecidos. Além disso, quando arrefecido até ao estado líquido, este combustivel de baixo peso ocupa 1/700 do espaço que ocupa no estado gasoso. Esta é a razão porque o hidrogénio é usado como combustivel para a propulsão de naves espaciais, que requerem combustiveis leves, compactos e com um conteúdo de energia elevado. Quando queimado com oxigénio puro os únicos productos são calor e água, por isso é o combustivel ideal para um desenvolvimento sustentável. A Câmara Municipal do Porto tem em funcionamento três autocarros alimentados a hidrogénio, portanto o hidrogénio não é só o combustivel do futuro, já é o do presente.

No seu estado livre e em condiçōes normais, o hidrogénio é um gás incolor, inodoro e insípido. A molécula de hidrogénio existe como dois átomos ligados entre si por electrões partilhados. Cada átomo é constituido por um protão e por um electrão que orbita o protão. Como a densidade do hidrogénio é 1/14 da densidade do ar, escapa-se com facilidade e existe em muito pouca quantidade na nossa atmosfera $(0.00005 \%)$. Na terra ele existe maioritariamente combinado com outros elementos, como o oxigénio na água e o carbono no metano.
Uma forma simples de produzir hidrogénio é através da electrólise da água. A electrólise separa a água nos seus elementos usando corrente eléctrica. Adicionando um electrólito, como o sal, melhora a condutividade da água e aumenta a eficiência do processo. No ânodo, que é o eléctrodo positivo, a água é oxidada a oxigénio $\left(\mathrm{O}_{2}\right)$, e no cátodo, que é o eléctrodo negativo, a água é reduzida a hidrogénio $\left(\mathrm{H}_{2}\right)$. Uma diferença de potencial de 1.24 V é necessária para separar o hidrogénio e o oxigénio, em água pura a $25^{\circ} \mathrm{C}$ e 1 atm de pressâo. Como a reacção de combustăo é uma reacção de oxidação/redução, a combustão do hidrogénio pode ser usada para gerar electricidade, numa pilha de combustivel.

As pilhas de combustivel são pilhas que convertem energia química directamente em energia eléctrica, operando continuamente graças à alimentação constante com um combustivel. A conversão ocorre por meio de duas reacções químicas parciais que ocorrem em dois eléctrodos separados por um electrólito apropriado: a oxidaçāo do combustivel no ânodo e a redução de um oxidante no cátodo. Utilizando o hidrogénio como combustível e o oxigénio como oxidante, na célula de combustivel dá-se formação de água. Os electrões que circulam do ânodo para o cátodo podem gerar trabalho eléctrico. Os protões gerados na reacção anódica (oxidação do hidrogénio) são conduzidos pelo electrólito até o cátodo, onde se ligam aos aniões $\mathrm{O}^{2}$, produto da redução do oxigénio, formando água. Várias animaçōes de células de combustivel a funcionar podem ser vistas em (http://www.h2fc.com/technology/fuelcells/general.shtml)

\section{Experimente}

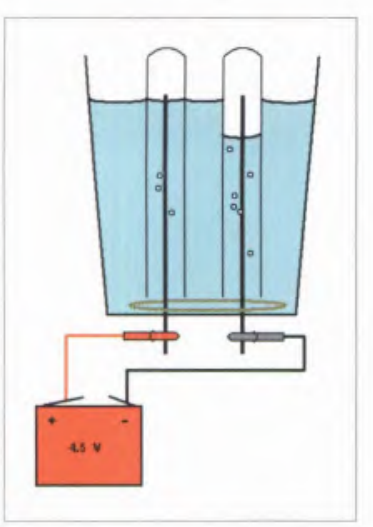

Material: copo de plástico transparente, ou recipiente de plástico transparente de fundo raso $(\sim 12 \mathrm{~cm}$ de altura), dois lápis grossos sem borrachas na ponta (os eléctrodos), uma pilha de $4.5 \mathrm{~V}$,dois ligadores de crocodilos, cola resistente à água (silicone), dois tubos de ensaio.

Preparação dos eléctrodos: Ferva os lápis em água algum tempo para amolecer a madei-

ra e enfraquecer a cola que mantém as duas peças de madeira juntas. Após algum tempo deve ser possivel separar as duas peças de madeira que envolvem o bastão de grafite (o eléctrodo). Enterrando uma chave de fenda numa das extremidades ajudará a descobrir a junta entre as duas peças.

Preparação da tina de electrólise: faça dois buracos no fundo do recipiente, suficientemente afastados para que possa pôr dois tubos de ensaio invertidos lado a lado sobre os eléctrodos que atravessarão os buracos. Faça-o com cuidado para não partir o plástico. Os buracos devem ser da largura dos bastōes de grafite, que devem caber à justa. Enfie os eléctrodos nos buracos por forma a que $1 \mathrm{~cm}$ saia pela parte debaixo da tina (ver figura) e cole vedando bem com cola de silicone.

Electrólise: Prepare 1 litro de soluções $1 \mathrm{M}$ dos electrólitos $\mathrm{NaCl}$ e $\mathrm{NaHCO}_{3}$. Faça diluições de 1:10 (i.e.: $1 \mathrm{M}, 0.1 \mathrm{M}, 0.01 \mathrm{M}$ ). Verfique que a pilha está desligada, use ligadores de crocodilo para ligar a pilha aos eléctrodos. Coloque um elástico (não esticado) em torno dos dois eléctodos dentro da tina: isto serve para afastar ligeiramente os tubos de ensaio do fundo, para que a circulação de corrente entre os eléctrodos possa ocorrer. Pode prender a tina com uma garra e uma noz a uma altura conveniente da bancada. Encha a tina com electrólito por forma a que os eléctrodos fiquem totalmente mergulhados ( $1 \mathrm{~cm}$ abaixo da superfície do liquido). Encha os tubos de ensaio até ao topo com electrólito e tape com o dedo tentando que o tubo não leve nenhuma bolha de ar. Inverta os tubos e mergulhe-os na solução por cima dos eléctrodos. Ligue a pilha e veja as bolhas começarem a formar-se. Colecte as bolhas até um dos tubos estar cheio pelo menos a $2 / 3 \mathrm{e}$ desligue a pilha. Levante o tubo do eléctrodo mantendo a entrada debaixo da superfície e levante ou baixe o tubo até que o menisco dentro do tubo esteja alinhado com o do líquido na tina. Meça a altura de gás que contém. Faça uma medida idêntica no outro tubo. Registe os resultados.

Nota: Se conseguir substituir a grafite por dois fios de platina (mais dispendioso) a reacção será mais eficiente e limpa.

\section{Questões:}

1 - Discuta o que entende por desenvolvimento sustentável.
2 - Escreva as reacçōes que se passam em cada um dos eléctrodos durante a electrólise da água.

3-0 que se está a formar no eléctrodo negativo? 


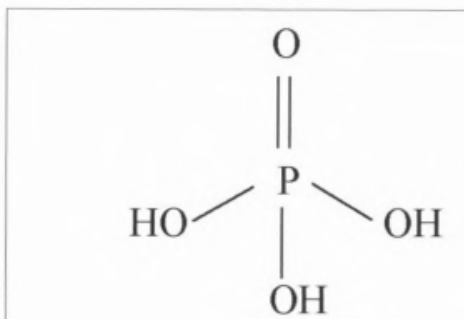

ác. fosfórico

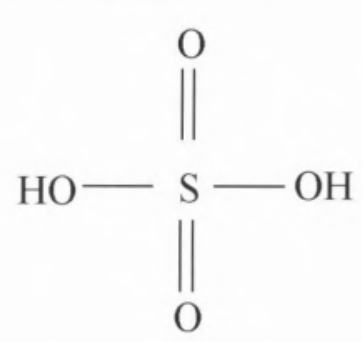

ác. sulfúrico "possuir" mais 1 electrão do que o seu número de electrões de valência (4 em vez de 3), logo fica o boro, na espécie formada, com carga formal negativa (nesta reacção, qual é a base e qual é o ácido de Lewis?)

Outro conceito excepcionalmente importante para os químicos orgânicos e que pode ser exemplificado através das figuras $1 \mathrm{~B}$ e $1 \mathrm{C}$ é o que inclui as noções de nucleofilicidade e electrofilicidade. Um nucleófilo é toda a espécie que "gosta" de núcleos, logo com alta densidade electrónica, enquanto que um electrófilo "gosta" de electrões, logo tem deficiência nestes. Assim, parece óbvio que o amoníaco e a água sejam espécies com carácter nucleófilo (ou nucleofílico), enquanto que o protão é um electrófilo. Como se poderão classificar o borano e o ião hidreto relativamente ao seu carácter nucleofilico / electrofilico? Repare-se que, de acordo com o que se disse, todas as bases de Lewis são nucleófilos e os ácidos de Lewis são electrófilos. A associação da basicidade com a nucleofilicidade e a da acidez com a electrofilicidade revela-se geralmente de grande utilidade; no entanto, deve ter-se também em conta que o conceito de basicidade / acidez está intimamente relacionado com a estabilidade da ligação química formada - controlo da reacção do ponto de vista termodinâmico -, enquanto que a nucleofilicidade / electrofilicidade são características que expressam a rapidez de formação de uma nova ligação - logo, controlo da reacção sob o ponto de vista cinético Nota 1 .

Antes de acabar esta secção, importa salientar que o fósforo e o enxofre, sendo do $3 .^{\circ}$ período, por vezes já não obedecem à regra do octeto, pois o átomo de fósforo pode aparecer rodeado por 10 electrões, e o do enxofre por 12 electrões (de acordo com o respectivo figura 2 Estruturas dos ácidos fosfórico e sulfúrico.

número de electrões de valência). Repare-se pois nas estruturas correspondentes aos ácidos fosfórico e sulfúrico - figura 2. Mas deixem-se os exemplos de compostos "năo orgânicos" e passem-se a aplicar os conceitos aqui sumariados para as moléculas, espécies e reacções orgânicas.

\section{Tipos de Reacções dos Compostos Orgânicos}

As ligações C-H e C-Cl, que se discutiram quando se introduziu o conceito de electronegatividade, são exemplos adequados para a explicação de como ocorrem as quebras homolíticas (homólises) e as quebras heterolíticas (heterólises).

Considere-se, por exemplo, um hidrocarboneto saturado, só constituído por ligações C-C e C-H. Sem a presença de grupos funcionais na molécula, são preciso condições drásticas para se dar a
A<smiles>CC(C)[CH]C(C)(C)CC(C)(C)CC(C)(C)C</smiles>

B figura 3

parte A: Homólise das ligações $\mathrm{C}-\mathrm{C}$ e C-H

parte $\mathrm{B}$ : Heterólise de uma ligação $\mathrm{C} \cdot \mathrm{Cl}$. 
figura 4 Primeira etapa da reacção da acetilacetona com um iâo alcóxido.

quebra das ligações desse hidrocarboneto, tipicamente temperaturas superiores a $300^{\circ} \mathrm{C}$ e condições de pressão superior à atmosférica. É o que ocorre, por exemplo, durante os processos de refinação do petróleo bruto (que, como se sabe, é essencialmente constituído por hidrocarbonetos saturados) e nas reacções de halogenação de alcanos (alcanos $=$ hidrocarbonetos saturados). Nessas condições experimentais, dá-se a homólise das ligações C-C e C-H - figura 3A. Da homólise resultam radicais e reacções radicalares (repare-se nas setas utilizadas $\longrightarrow$ ).

No caso dos haloalcanos ( $=$ halogenetos de alquilo), por exemplo um cloroalcano, caracterizado pela ligação $\mathrm{C}-\mathrm{Cl}$, a quebra da ligação está facilitada, sob condições reaccionais suaves, pelo facto de estar polarizada, ganhando o $\mathrm{Cl}$ o par de electrões da ligação. Quando a quebra da ligação se dá deste modo, ocorre uma heterólise e formam-se dois iões, um com carga negativa ( $\mathrm{Cl}$-) e outro com carga positiva (um carbocatião ou ião carbónio) - figura 3B.

figura 5 Três exemplos de reacções de substituição.

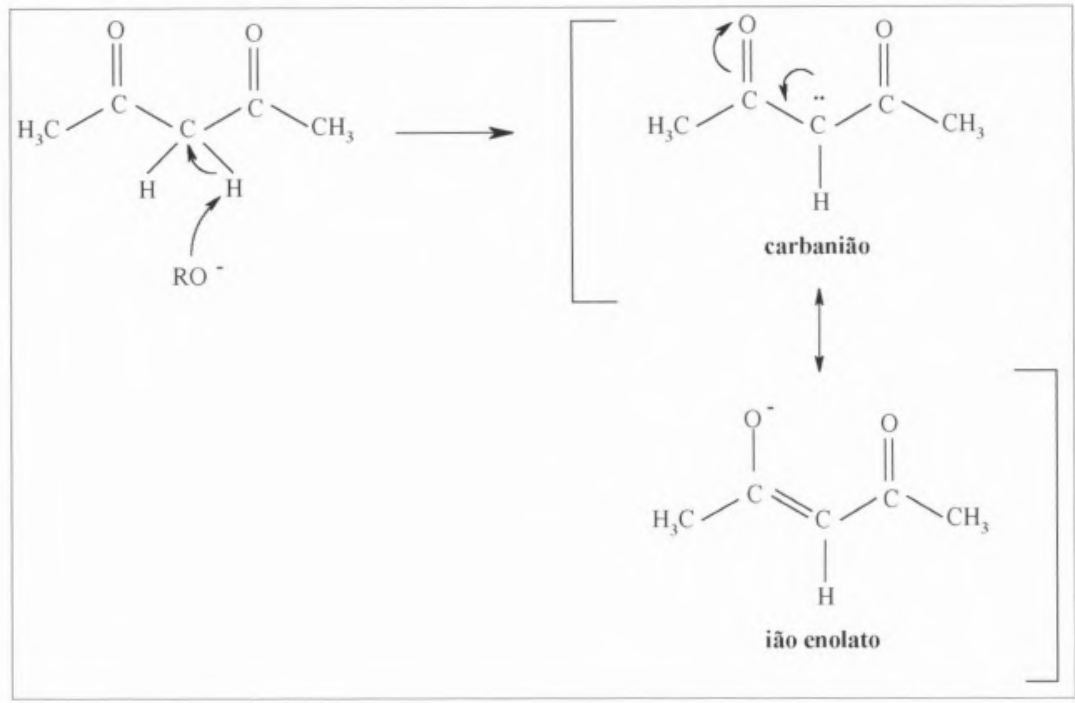

Não se pense, no entanto, que a quebra de ligações $\mathrm{C}-\mathrm{H}$ é sempre difícil, tudo depende da estrutura da molécula. Por exemplo, na acetilacetona - figura 4 - a acção de uma base relativamente fraca (por exemplo, um ião hidróxido ou alcóxido, em solução aquosa ou alcoólica) consegue facilmente retirar um protão. Porquê? Pode explicar-se tal comportamento pelo facto de estarem presentes na molécula átomos electronegativos, tipicamente os dois átomos de oxigénio. Com efeito, eles têm tendência a "puxar" os electrões para si, e isso faz com que as ligações $\mathrm{C}$ - $\mathrm{H}$ sejam mais fracas - a acetilacetona apresenta algum carácter ácido - pelo que a saída de um protão fica facilitada sob estas condições reaccionais. Para além disso, a electronegatividade dos oxigénios também justifica o movimento electrónico representado na espécie de carbono com carga negativa (carbanião ou carboanião), afirmando-se então que a espécie está adicionalmente estabilizada por ressonância (repare-se nas setas utilizadas $\longleftrightarrow)^{\text {Nota } 2}$ - figura 4. A segun- da estrutura de ressonância é denominada de ião enolato.

As setas curvas que aparecem ao longo das figuras 3 e 4 exemplificam um "mecanismo" que permite explicar a transformação de um dado reagente num produto determinado; tal mecanismo serve para justificar a ocorrência de um certo tipo de reacção química. Apesar de não poderem ser "provados", os mecanismos são descrições valiosas do que provavelmente se passa a nivel molecular, e são sempre baseados na recoIha de dados experimentais. Como é óbvio, os mecanismos das reacções orgânicas vão sofrendo correcções de modo a serem permanentemente actualizados à luz das novas descobertas.

Assim, apesar dos cerca de 7 milhões de entre os 8,5 milhões de compostos químicos conhecidos serem orgânicos, verifica-se que é possivel sistematizar a sua química de tal modo que as reacções típicas que sofrem se resumem a quatro grandes grupos, a saber:

- Reacções de substituição;

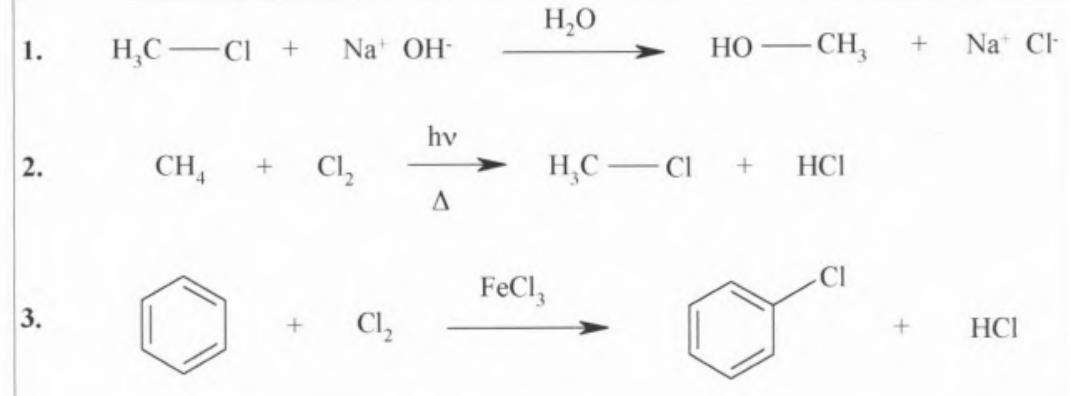



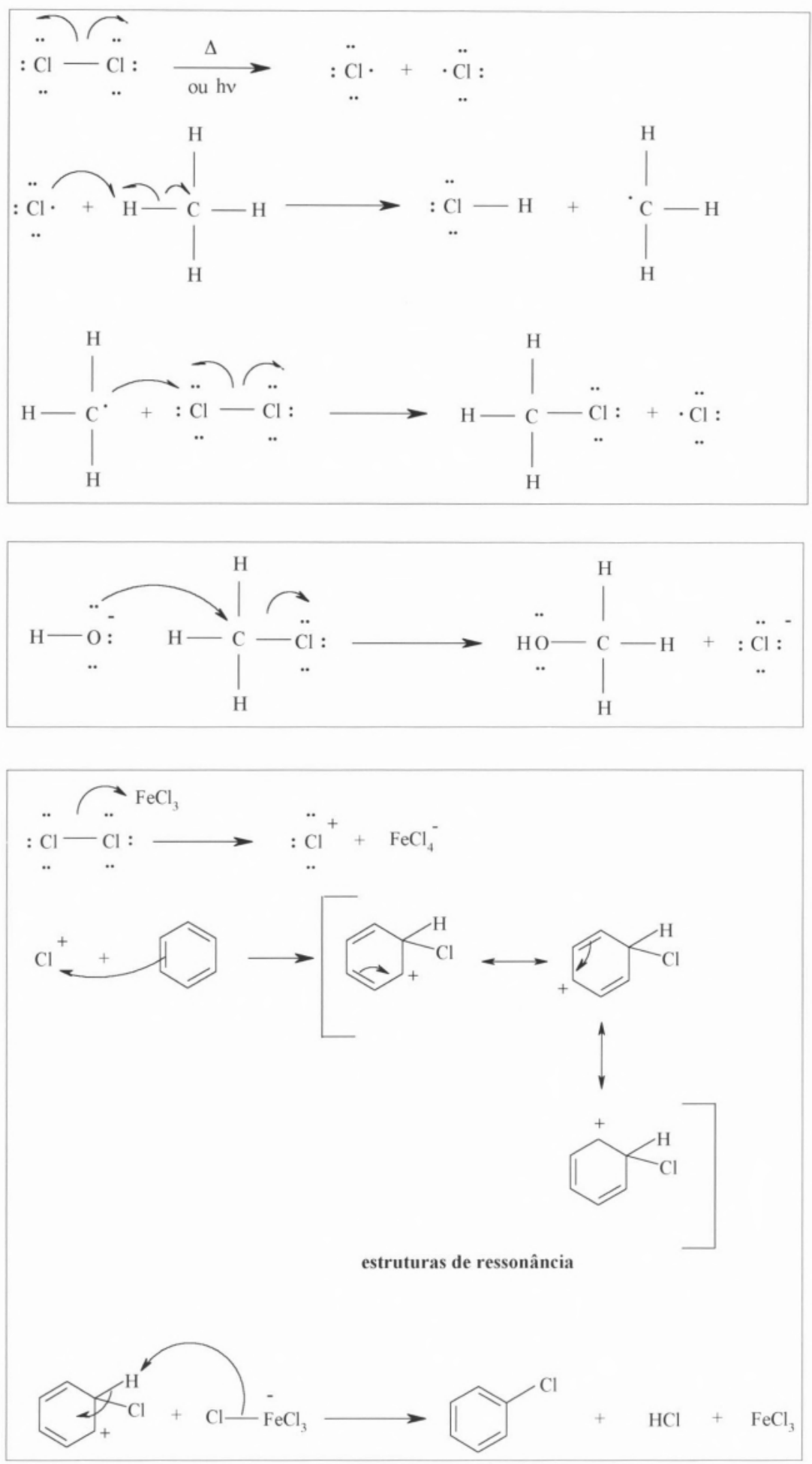

- Reacções de adição;

- Reacções de eliminação;

- Rearranjos.

Na realidade, o que dita a ocorrência de um ou de vários tipos de reacções para um dado composto são os grupos funcionais nele presentes e as condições reaccionais adoptadas. Apesar de uma dada família de compostos apresentar geralmente uma reactividade semelhan- figura 6 Mecanismo radicalar de cloração do metano.

figura 7 Exemplo de um mecanismo de substituição nucleofilica aplicado ao clorometano figura 8 Exemplo de um mecanismo de substituição electrofilica aplicado ao benzeno.

\section{Reacções de substituição} apresentar um ou mais mecanismosbase, dependendo a sua ocorrência quer das características estruturais específicas das moléculas em questão, quer também das próprias condições experimentais sob as quais a transformação decorre.

Passam-se então a apresentar exemplos significativos dos tipos de reacções acima referidos.
$\mathrm{Na}$ figura 5 estão representadas três reacções de substituição. Na primeira, 0 clorometano sofre reacção com hidróxido de sódio em solução aquosa para originar o metanol e cloreto de sódio. A substituição justifica-se pelo facto de, na molécula de clorometano, o $\mathrm{Cl}$ ter sido substituído pelo grupo $\mathrm{OH}$. A segunda representa a cloração do metano para dar clorometano e ácido clorídrico. Já se 


\section{figura 9 Três exemplos de reacçōes de adição.}

figura 10 Exemplo de um mecanismo de adição electrofilica de água a um alqueno.

figura 11 Exemplo de um mecanismo de adição nucleofilica de um ião hidreto à acetona.

referiu anteriormente que a quebra das ligações C-H dos alcanos é muito difícil, e neste caso o hidrogénio é substituído pelo cloro. São necessárias temperaturas altas ou acção de radiação, pelo que as reacções envolvem a formação de radicais. O terceiro exemplo é também uma reacção de substituição mas, neste caso, de um composto aromático, o benzeno. Dá-se a substituição de um hi-
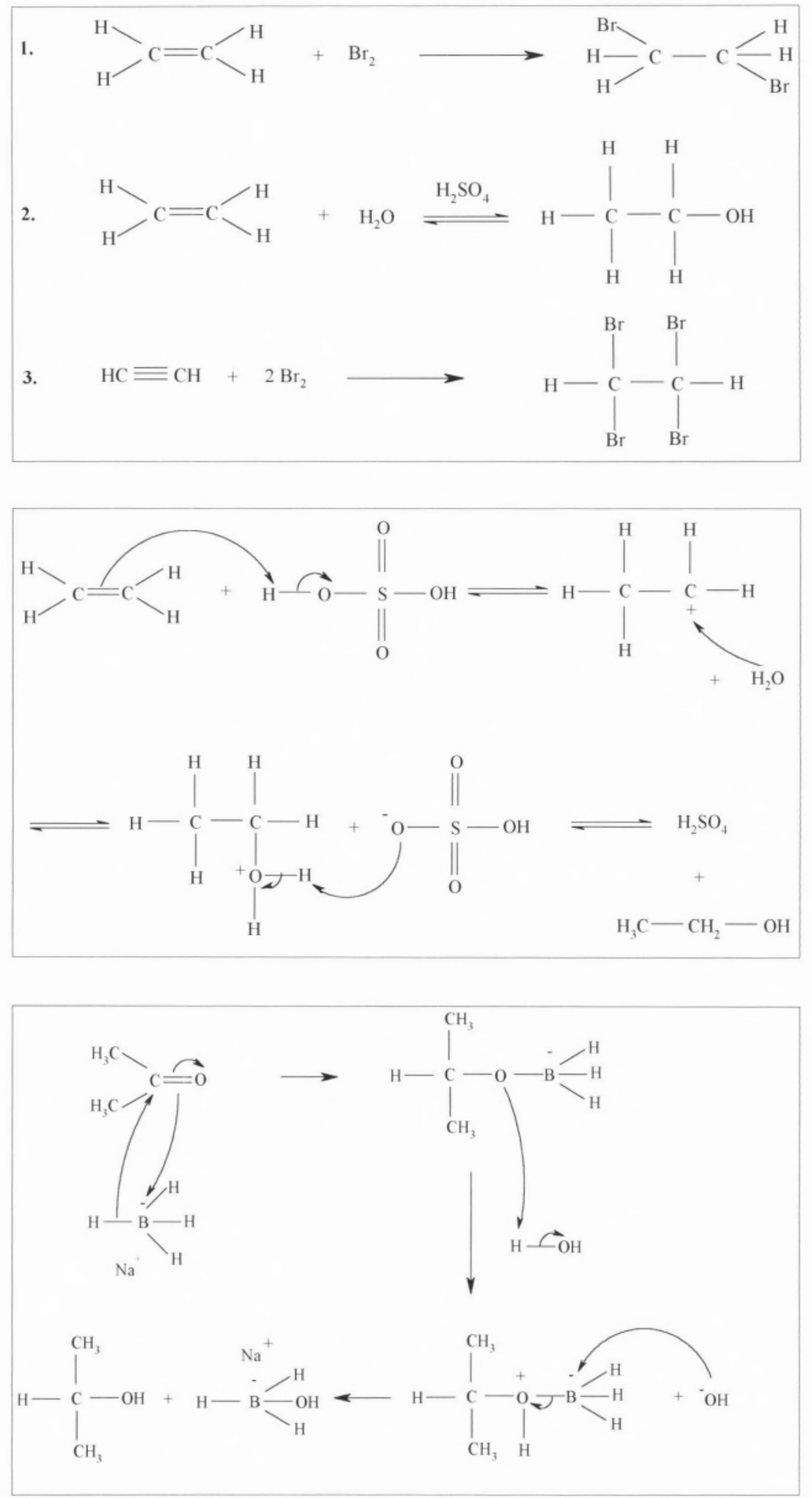

drogénio por cloro, originando o clorobenzeno e ácido clorídrico. Neste caso, a quebra da ligação $\mathrm{C}-\mathrm{H}$ não está tão dificultada, devido à presença do sistema aromático no reagente, que permite a ocorrência da substituição por um outro processo.

As reacções de substituição são características de compostos saturados - al- canos, haloalcanos e álcoois -, e também dos compostos aromáticos. Como se referiu anteriormente, as reacções dos alcanos são do tipo radicalar - apresenta-se como exemplo o mecanismo da cloração do metano na figura 6 -, as reacções de substituição dos haloalcanos e álcoois são substituições nucleofílicas e as dos compostos aromáticos são 

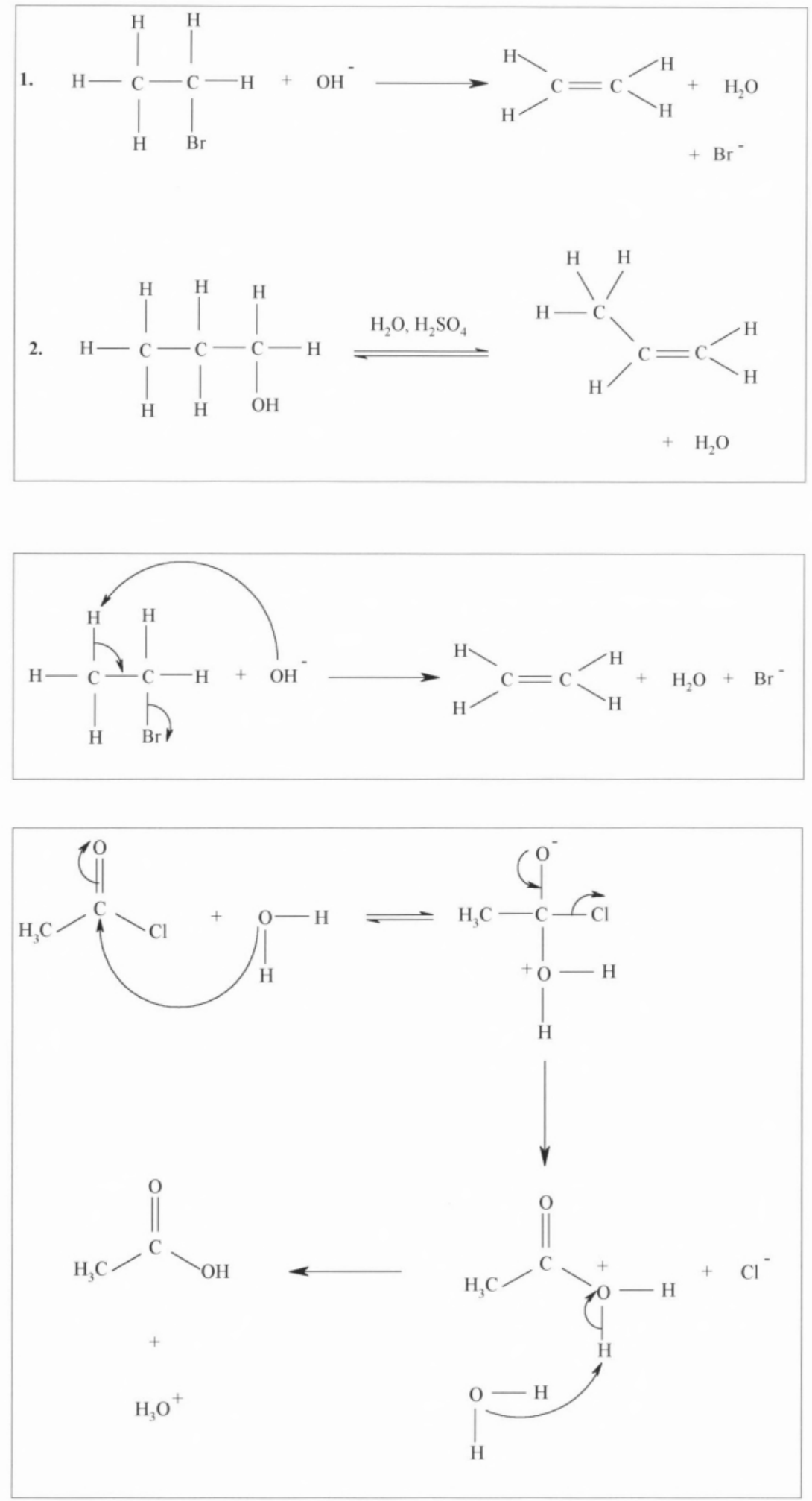

tipicamente substituições electrofilicas. Porquê?

Os álcoois e haloalcanos, ao sofrerem substituição, sofrem o primeiro ataque por espécies com carácter nucleofílico, tal como pode ser observado na figura 7 - a substituição nucleofílica do cloro do clorometano pelo grupo $\mathrm{OH}$ para originar metanol. Neste tipo de mecanismo, o ataque do nucleófilo ocorre ao mesmo tempo que a quebra heterolítica da ligação C-Cl.

No caso da substituição electrofílica do benzeno para originar clorobenzeno, repare-se que o ataque inicial ao composto aromático é feito por um electrófilo, representado de modo simplificado por $\mathrm{Cl}^{+}$. É necessária a presença de um ácido de

figura 12 Dois exemplos de reacções de eliminaçâo.

figura 13 Exemplo de um mecanismo de eliminação aplicado a um bromoalcano.

figura 14 Exemplo de um mecanismo de adição nucleofilica - eliminação aplicado a um cloreto de alcanoílo,

Lewis (neste caso $\mathrm{FeCl}_{3}$ ) para que o cloro passe a ter o carácter electrofilico necessário à espécie atacante e que deste modo justifica o nome da reacção-tipo aqui exemplificada - figura 8.

\section{Reacções de adição}

As reacções de adição, como o nome indica, consistem na adição de uma ou mais espécies químicas a uma dada 
figura 15 Exemplo de uma reaç̧âo que envolve um rearranjo e respectivo mecanismo.

molécula, de modo a dar um composto final que inclui todos os componentes. As reacções de adição são típicas de compostos com ligações múltiplas, particularmente com ligações carbono carbono duplas ou triplas. Na figura 9 estão exemplificadas três reacções de adição: na primeira reacção ocorre a adição de bromo ao eteno para originar 1,2-dibromoetano, a segunda mostra a formação de etanol a partir da hidratação do eteno e a terceira representa a adição de duas moléculas de bromo ao etino para originar o tetrabromoetano.

As reacções de adição ilustradas na figura 9 são do tipo electrofílico, ou seja, a primeira etapa do mecanismo reaccional consiste na adição de um electrófilo à grande densidade electrónica típica das ligações insaturadas carbono - carbono. Exemplifica-se o mecanismo da hidratação electrofilica do eteno para originar etanol, em que o primeiro passo consiste na adição do electrófilo $\mathrm{H}^{+}$à ligação $\mathrm{C}=\mathrm{C}$ - figura 10 . $\mathrm{O}$ ácido sulfúrico funciona como catalisador da reacção.

Os compostos de carbonilo - aldeídos e cetonas - sofrem também reacções de adição, mas estas ocorrem através do ataque de nucleófilos ao carbono do grupo carbonilo. Com efeito, o oxigénio "puxa" os electrões da ligação $\mathrm{C}=\mathrm{O}$, de acordo com o exposto anteriormente, o que faz com que o átomo de carbono seja susceptivel ao ataque de nucleófilos. Um exemplo de adição nucleofílica é apresentado na figura 11, em que ocorre a adição de um ião hidreto à acetona, e a espécie intermediária reage como base com uma molécula de água para originar o propan-2-ol.

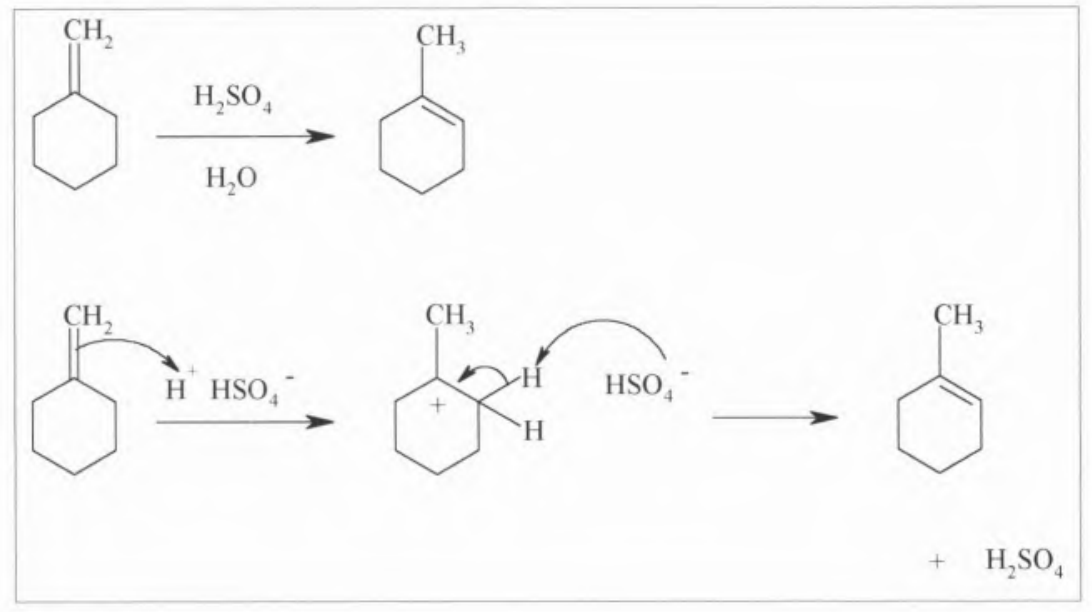

\section{Reacções de eliminação}

As reacções de eliminação competem frequentemente com as reacções de substituição nucleofilica e, por isso, ocorrem também com compostos saturados tais como haloalcanos e álcoois. Com efeito, como já anteriormente referido, os nucleófilos têm sempre algum carácter básico, de modo que este tipo de reacção é caracterizado pelo facto de se dar o ataque de uma base à molécula orgânica, o que a faz perder elementos que, por sua vez, vão constituir outra espécie química mais pequena e simultaneamente leva à formação de compostos com ligações carbono - carbono insaturadas, duplas ou triplas. Na figura 12 apresentam-se dois exemplos de reacções de eliminação: na primeira reacção, o OH vai retirar um protão do átomo de carbono adjacente ao que está ligado ao átomo de bromo, o que origina água, ião brometo e eteno. No segundo caso, o propan-1-ol, em presença de água e de um ácido não nucleófilo $\mathrm{H}_{2} \mathrm{SO}_{4}$ - origina o prop-1-eno. Exemplifica-se na figura 13 o mecanismo que explica a formação do eteno a partir do 1-bromoetano.

Os ácidos carboxilicos e seus derivados - tipicamente os cloretos de alcanoílo (ou acilo), anidridos, ésteres e amidas sofrem reacções do tipo adição nucleofílica-eliminação. Com efeito estes compostos, depois de sofrerem adição nucleofilica no átomo de carbono do grupo carbonilo, têm tendência a restabelecer o grupo carbonilo por eliminação de um fragmento da espécie intermediária, como se pode observar no exemplo apresentado na figura 14 . Neste, a água adiciona-se nucleofilicamente ao átomo de carbono do $\mathrm{C}=\mathrm{O}$, reagindo o intermediário de modo a originar no final o ácido acético.

\section{Rearranjos}

As moléculas orgânicas sofrem reorganização da sua estrutura com alguma facilidade de modo a originar, de acordo com as condições experimentais adoptadas, compostos com uma estrutura mais estável. Mostra-se na figura 15 um exemplo de um alqueno terminal que se rearranja em meio sulfúrico aquoso para originar um alqueno interno (termodinamicamente mais estável), bem como o respectivo mecanismo de transformação.

\section{Comentário Final}

De um modo simplista, pretendeu-se neste trabalho evidenciar quais os conceitos básicos que é importante reter e que devem implicitamente ser tidos em conta se se pretende compreender e explorar a Química associada ao comportamento dos compostos orgânicos.

Há quem compare a Química Orgânica à Matemática, isto é, ambas requerem um tipo de raciocínio que é muito lógico. No entanto, a lógica só faz sentido (só é lógica) quando as suas bases de funcionamento são bem apreendidas. A fase posterior ao processo de apreensão pode ser, obviamente, muito compensadora: a partir daí, o conhecimento adicional transforma-se em prazer. Esperase, pois, que este texto possa ter contribuído para despertar algumas pessoas para esse prazer, mas não se 
pense que, para isso, não seja necessário muito esforço e empenhamento. Aliás, como para tudo na Vida.

\section{Bibliografa}

Existem muito bons livros de texto em Química Orgânica. Seguem-se três sugestões, das quais se retirou alguma informação contida neste trabalho:

G. Solomons, C. Fryhle, "Organic Chemistry", 7. 'Ediçāo, John Wiley and Sons, Inc., 2000;
K. P. C. Vollhardt, N. E. Schore, "Organic Chemistry", 4. Edição, W. H. Freeman and Company, 2002;

M. Hornby, J. Peach, "Foundations of Organic Chemistry", 1. Edição, Oxford University Press, 1995.

\section{Notas}

1 Não se pense, no entanto, que a "força" das bases e dos ácidos acompanha no mesmo sentido a força dos nucleófilos e dos electrófilos, respectivamente. Verifica-se muitas vezes que uma base fraca é um bom nucleófilo, uma vez que se pode formar uma ligação fraca, mas rapidamente, nessas condições experimentais.

2 No entanto, a espécie iónica real é um híbrido de ressonância, ou seja, ela é descrita pelas formas de ressonância, mas nenhuma existe por si só nem pode ser isolada (em total paralelismo com o que acontece com as estruturas de ressonância que descrevem a molécula do benzeno).
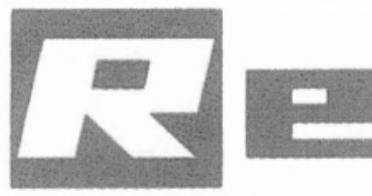
t
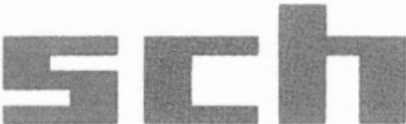

1509001

Agitadores de peneiros/peneiros
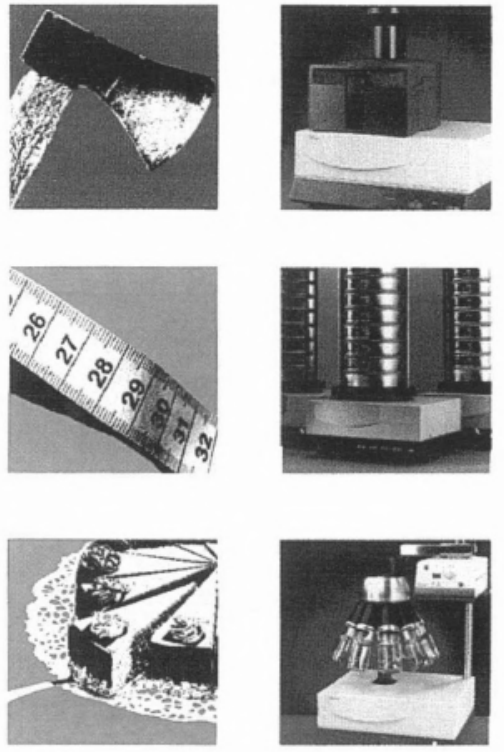

Análise granulométrica automática

CAMSIZER / Crystalsizer

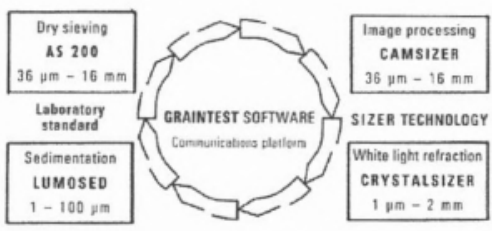

Peça-nos o contacto do agente mais próximo, através dos telefones:

21-352 7293

LISBOA

Campo Mártires da Pátria, 109 http://www.en-equipamentos.pt
22-618 4232

O 9mpartadar Exelusiua 


\section{Eur

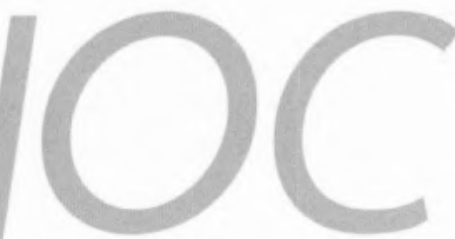 \\ European Journal of Organic Chemistry}

\section{YourJournal}

First Impact Factor: 2.150

Rapid publication times especially for short communications

Now supported by ten national chemical societies (Belgium,

France, Germany, Greece, Hungary - together with the Hungarian

Academy of Sciences, Italy, The Netherlands, Portugal, Spain)

Authors' work exhibited on the cover

Attractive personal member subscription rates available;

see: www. EurJOC.com

More color

\section{European Journal of Organic Chemistry}

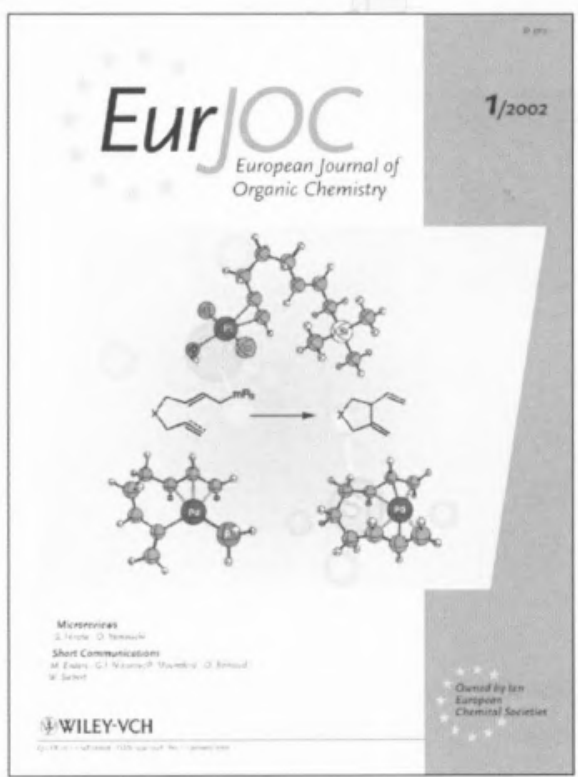

Wiley-VCH

\section{4 issues}

ISSN Print 1434-193X

ISSN Electronic 1099-0690

The European Journal of Organic

Chemistry publishes full papers, short communications and microreviews covering the entire spectrum of synthetic organic, physical organic and bioorganic chemistry, as well as that of natural products. Example microreviews from past and forthcoming issues are listed on this page.

Senior Editor: Henning Hopf (Germany)

\section{FREE SAMPLE COPY}

The European Journal of Organic Chemistry is available online through Wiley InterScience. Visit Wiley InterScience (www.interscience.wiley.com) for complete details and see the FREE full text virtual sample copy.
Order Your Copy now:

Just copy, fill in and fax to: $+49 /(0) 6201 / 606-172$

\lrcorner Please send me a free sample print copy

\lrcorner Please enter our/my 2002 subscription to:

European Journal of Organic Chemistry

2002, ISSN Print 1434-193X 2002, ISSN Electronic 1099-0690 at the institutional rate*

print electronic

\lrcorner Europe $\lrcorner € 2498 \quad J € 2498$

\lrcorner Switzerland $\lrcorner \mathrm{sFr} 4328 \quad\lrcorner \mathrm{sFr} 4328$

\lrcorner All other

countries JUS\$3158 JUS\$3158

* For a $5 \%$ premium, institutions can choose both print and electronic access, a

For members of the owner societies from Belgium, France, Germany, Greece, Hungary, Italy, The Netherlands, Portugal and Spain, at the personal rate: print

J Europe $\lrcorner € 298$

Switzerland J SFr 588

J All other

countries JUS\$318

Prices include postage and handling charges.

Please tick: $\square$ private $\square$ business

Name

Address

City/Postcode

Country

Membership-No.

Date/Signature

Please return this order to your local bookseller or to:

Customers in Germany, Austria and Switzerland:

Wiley-VCH Customer Service

P.O. Box 101161 .

D-69451 Weinheim, Germany Phone: +49 (0) 6201-606 147

Fax: +49 (0) 6201-606 172

e-mail: subservice@wiley-vch.de

Customers in all other areas:

John Wiley \& Sons, Ltd.

Journals Administration Department 1 Oldlands Way

Bognor Regis West Sussex, P022 9SA, England

Phone: +44 (0) 1243-779 777

Fax: +44 (0) 1243-843232

e-mail:cs-journals@wiley.co.uk 